\title{
The Effects of Sling Exercise on Gluteus Muscle Strength and Gait Velocity in Females with History of Chronic Low Back Pain
}

\author{
Nam-goo Kang, PT, MSc ${ }^{1}$; Jae-Seop Oh, PT, Ph.D ${ }^{2}$ \\ ${ }^{1}$ Department of Rehabilitation Science, The Graduate School, Inje University \\ ${ }^{2}$ Department of Physical Therapy, College of Biomedical Science and Engineering, Inje University
}

Background Gluteal muscle weakness or dysfunction leads to low back pain. Gluteal muscle is important for posture, balance, and independent gait. Despite the well-established link between with history of chronic low back pain (CLBP) and gluteal muscle weakness, there is little research available on direct exercise interventions. Whether sling exercises increase gluteal muscle strength in those with chronic low back pain has not been studied.

Purpose To determine the changes in gluteus maximus and gluteus medius muscle strength, gait velocity, pain, and low back disability following an intervention using sling exercise for four weeks in females with a history of CLBP.

Study design Cross-sectional study

Methods This study involved 27 females with a history of CLBP who visited the $\mathrm{H}$ fitness center. The participants' pain intensity was measured using the visual analogue pain scale. Disability was measured using the Korean Oswestry Disability Index. A force measurement device was used to collect data on gluteal muscle strength. The participants walked for five minutes at a preferred walking speed on a treadmill, and the average walking speed was measured during gait and then re-measured after exercise.

Results Pain intensity and disability were found to significant decrease after sling and common exercise groups. Significant increased post-intervention versus pre-intervention were seen in the hip abductor strength and gait velocity $(p<0.05)$. No significant differences were seen in the hip extensor strength $(p>0.05)$. These results show that hip abductor strength was significantly different between before and after sling exercise.

Conclusions Sling exercises may be effective for stability during the gait pattern and may be recommended to improve the gluteal strength and lumbo-pelvic stability for those with chronic low back pain.

Key words Chronic low back pain; Gait velocity; Gluteus medius strengthening; Gluteus muscle weakness; Sling exercise.

J Musculoskelet Sci Technol 2021:5(2): 59-66 Published Online Dec 31, 2021 pISSN 2635-8573 eISSN 2635-8581

\section{Article History}

Received 31 Oct 2021 Revised 8 Nov 2021 (1st)

Revised 22 Nov 2021 (2nd) Accepted 22 Nov 2021

\section{CONTACT}

ysrehab@inje.ac.kr Jae-Seop Oh, Department of Physical Therapy, College of Biomedical Science and Engineering, Inje University

This is an Open-Access article distributed under the terms of the Creative Commons Attribution Non-Commercial License (http://creativecommons. org/licenses/by-nc/4.0) which perits permits unrestricted non-comercial use, distribution, and dium, provided the origina work is properly cited.

\section{INTRODUCTION}

Chronic low back pain (CLBP) is one of the most common musculoskeletal problems worldwide. ${ }^{1-4}$ There are many risk factors for CLBP, such as excessive body weight, age, insufficient muscle strength, and mechanical stress. ${ }^{1}$ Among these factors, muscle weakness or dysfunction of the muscle contraction leads to low back pain. Previous authors have suggested that gluteal muscle weakness and hip joint dysfunction strongly relate to chronic low back pain in middle age women. ${ }^{2}$ Hip extensor and abductor weakness may lead women to adopt abnormal movement strategies, resulting in compensatory motion in the lower back. $^{5-7}$ Therefore, gluteal muscle weakness or hip contrac- 
tion dysfunction can lead to low back pain. ${ }^{2}$ The gluteus maximus (Gmax) and the gluteus medius (Gmed) contribute extensively to weight-bearing movement by assisting in stabilizing the lumbo-pelvic-hip complex. , $^{1,5,8-10}$

The Gmax has the most important effect during the first $50 \%$ of the trunk extension, and weakness in the Gmax increases the stress in the intervertebral disc and the lumbar spine ligaments. ${ }^{2}$ Also, a decrease is shown in the crosssectional area of Gmax for women with chronic low back pain, as well as a decrease in walking speed in subjects with chronic low back pain. ${ }^{11}$ The Gmed is characterized by weakness and tenderness in a subject with chronic low back pain. ${ }^{10}$ The height difference in the pelvis due to Gmed weakness also suggested that the Gmed strengthening is effective for routinely standing subjects with low back pain. $^{6,12}$ In addition, activated Gmed are important for posture, balance, and independent gait. ${ }^{6,12}$ However, few studies have investigated which exercise is effective for strengthening this muscle and reducing CLBP.

Previous researchers have noted that CLBP is characterized by impaired gait, such as low walking speed, short stride length, and inflexible coordination of the thoraxpelvis segment. ${ }^{13-15}$ Lamoth et al. reported the stability of the lumbo-pelvic-hip complex is an important consideration because it is largely related to injury prevention, by transferring load from the lower limbs to the pelvis and spine and stabilizing the pelvis during walking. ${ }^{9}, 16,17$ Henchoz et al. also reported comparing the walking efficiency and walking speed between a chronic low back pain group and a control group, and it was concluded that chronic low back pain represents a slow walking speed and that it is a result of the compensation strategy by avoiding hip extension and the lumbar spine., ${ }^{911}$ Barzilay and Lee et al. also examined the association between the hip abductor muscle weakness and independent gait, and balance recovery during the stance phase of gait. 6,13

The clinical presentation of the association effects of hip muscle strengthening and stability between independent gait and the hip muscle could be explained by lumbo-pelvic-hip control in the regulation of gait coordination in CLBP. ${ }^{9,15,16}$ Despite the well-established link between chronic low back pain and gluteal muscle weakness, there is little research available on direct exercise interventions. One such exercise intervention is a sling exercise. This includes a specific exercise method. ${ }^{18}$

Recently, a lumbar stability exercise using a sling has been applied to treat low back pain. ${ }^{8,19,20}$ Sling exercise enables proprioceptive exercise training for recovery of neuromusculoskeletal dysfunction and strengthening deep muscle that engage in stability. ${ }^{21}$ Furthermore, sling exer- cise supports or suspends the pelvis and hip joint muscle without pain, normalizes muscle response patterns, retrains muscle motor units, and improves damaged postural alignment abilities. ${ }^{8,18-21}$ However, the effect of the sling exercise method increasing gluteus muscle strength in those with chronic low back pain has not been studied.

The purpose of the present study was to determine the changes in Gmax and Gmed muscle strength, gait velocity, pain, and low back disability following an intervention using sling exercise for four weeks in females with a history of CLBP. We hypothesized that the sling exercise group (SEG) would significantly increase their gluteal muscle strength and gait velocity compared to the common exercise group (CEG). We also hypothesized that the SEG would significantly improve their pain and low back disability.

\section{METHODS}

\section{Participants}

This study involved 27 females with a history of CLBP who visited the $\mathrm{H}$ fitness center. Inclusion criteria included low back pain lasting more than three months and then those who had been diagnosed with low back pain at hospitals within the past one year. Symptoms have been maintained at least one week before the study began.

Exclusion criteria included hip joint dislocation, fracture, structural malformation, severe pain, neurological symptoms, history of medical surgery or treatment within the last one year, and any other rehabilitation intervention at the beginning of the study. Participant characteristics are shown in Table 1. Ethics approval of this study was obtained from the Inje University (INJE 2018-04-036-005), and written informed consents were obtained from all subjects before the data collection commenced. Sixteen subjects of the 27 chronic low back pain females group applied the sling exercise and 11 subjects performed common exercises, which included weight lifting, swimming, in-door cycling, and climbing. Five of the 16 subjects in the common exercises group first recruitment are unable to complete the study due to personal reasons.

\section{Procedure}

A total of two hip sling exercises were examined in this study. The exercises were performed on both legs (dominant side first), and then the exercises were carried out under two conditions of the gluteus muscles (Gmax, Gmed), namely A) Sling hip bridge exercise (SHB), and B) Sling hip abduction exercise (SHA) in randomized order (Figure 1). Sling exercise were performed after 30 -second resting 
Table 1. General characteristics of the subjects

\begin{tabular}{cccc}
\hline Characteristics & SEG $(n=16)$ & CEG $(n=11)$ & $p$ \\
\hline Age (years) & $38.31 \pm 10.15$ & $37.72 \pm 11.57$ & 0.596 \\
\hline Height $(\mathrm{cm})$ & $163.00 \pm 4.80$ & $162.27 \pm 2.45$ & 0.078 \\
Body weight $(\mathrm{kg})$ & $59.68 \pm 6.51$ & $56.00 \pm 4.52$ & 0.173 \\
\hline VAS (cm) & $6.63 \pm 2.18$ & $4.73 \pm 2.68$ & 0.032 \\
\hline Low back disability $(\%)$ & $31.19 \pm 15.60$ & $18.45 \pm 12.63$ & 0.047 \\
\hline
\end{tabular}

Data are expressed as mean \pm standard deviation; ${ }^{*} p<0.05$.

Abbreviations: SEG, sling exercise group; CEG, common exercise group; VAS, visual analog scale.

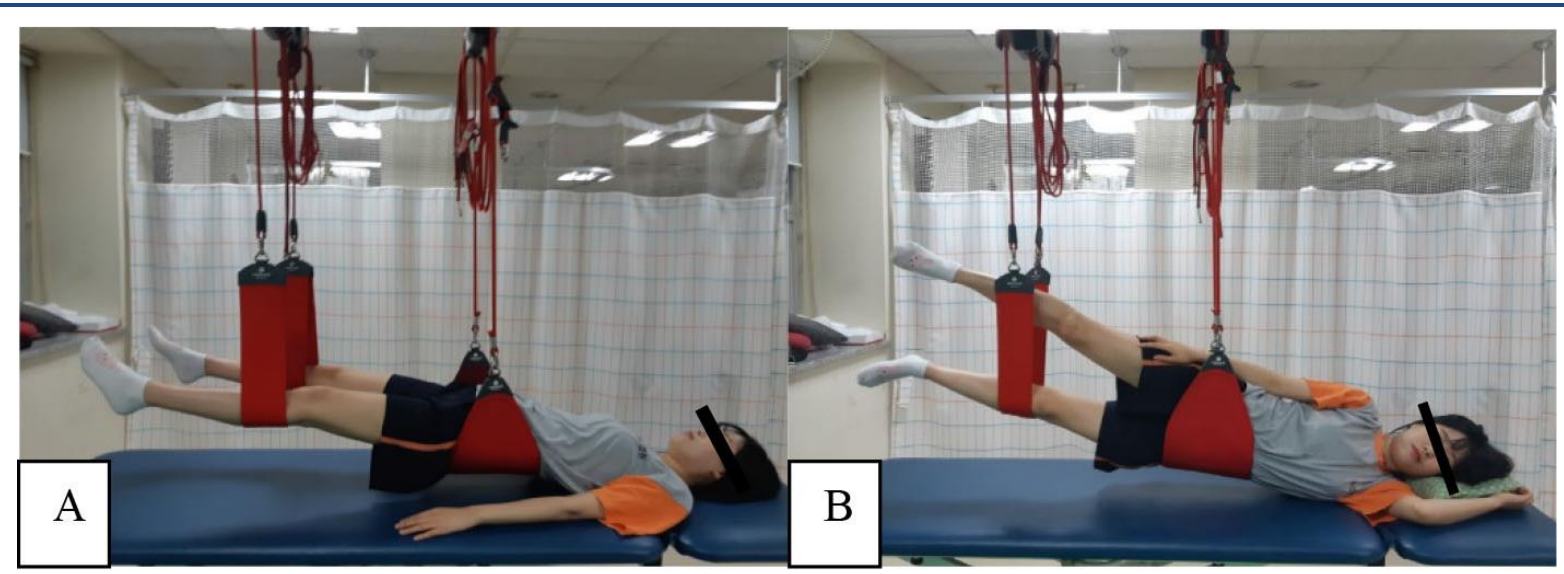

Figure 1. Sling hip bridge exercise (A) and sling hip abduction exercise (B).

time per session and five minutes between each exercise. At the start of the hip bridge exercise, the subjects adopted a supine position with their arms parallel to the floor. ${ }^{8,18-22}$

Each action was performed six to eight times for one set and holding time 6 seconds. The overall set was repeated three times, and there was a 90 -second rest period after each set. The intervention was conducted for a total of four weeks and low back pain intensity and disability index, gait velocity, and gluteus strength were repeatedly evaluated at four weeks after sling exercise group (SEG) in the study. The common exercise group (CEG) performed exercises to improve whole body strengthening. Each exercise was performed for 30 minutes, two times per week, for four weeks.

\section{Measurement of back pain and low back disability}

Pain level was evaluated using a visual analog scale (VAS; $10 \mathrm{~cm}$ ). Zero indicated no pain, and $10 \mathrm{~cm}$ indicated the highest pain level. ${ }^{23,24}$ Low back disability was evaluated using the Korean Oswestry Disability Index (KODI). The KODI is a nine-item measure of current activity limitation from LBP. ${ }^{25,26}$ It is an easy to use, reliable assessment of the level of back pain interference with physical activity and gait.
Measurement of gluteal muscle strength

The Gmax was measured at $90^{\circ}$ of knee flexion and prone position. ${ }^{27}$ The upper limbs were strapped by one examiner and Gmax muscle strength was measured at peak hip extension the with the force measurement device (Figure 2). 5,27

The force measurement device was positioned at the vertical middle point on the floor with non-elastic straps to

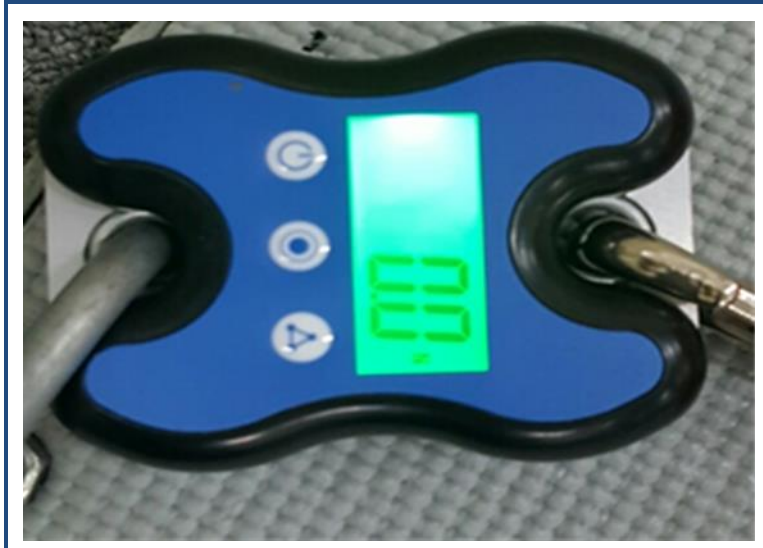

Figure 2. Force measurement device. 
middle aspect thigh. The Gmed was positioned at full extension of the knee and the other side limb bent knee flexion with supine position. ${ }^{28}$ The lower limbs were strapped with hip abduction and peak Gmed muscle strength was measured with the force measurement device (Figure 3). The force measurement applied to resistance in a fixed position, and the subjects being tested exerted a five-second isometric maximum voluntary contraction. ${ }^{28}$ This was followed by three trials of maximum isometric effort. For data analysis, the mean value was used for the three trials of maximum muscle strength.

\section{Statistical analyses}

Data were statistically analyzed using the IBM SPSS Statistics for Windows Program (ver. 18.0 for Windows; SPSS Inc., Chicago, IL, USA). All data using paired $t$-test was performed for participants for comparisons of gluteus strength, gait velocity, KODI, and VAS. Pearson correlation coefficient was conducted to examine whether there were differences in gluteus muscle strength and gait velocity for chronic low back pain. Statistical significance was accepted at values of $p<0.05$.

A two-way mixed analysis of variance was used to determine the time-by-group interaction effect or main effect. The within-group factor was time (pre-intervention vs. post-intervention) and the between-group factor was group (SEG vs. CEG). If a significant time-by-group interaction effect or main effect was detected, a post hoc $t$ test was used. The significances of the between-group differences in the demographics of the SEG and CEG were analyzed by independent $t$-tests.

\section{RESULTS}

A significant time-by-group interaction was observed for the SEG, CEG of the VAS, KODI, Gmed muscle strength, and gait velocity. An independent-sample $t$-test demonstrated that the KODI (Table 2; $F=2.090, p=0.032$, mean difference $=9.00$ ), significantly decreased in the SEG compared to the CEG. The gait velocity (Table 2; $F=10.475$, $p=0.003$, mean difference $=0.25$ ) significantly increased in the SEG compared to the CEG. In addition, a significant main effect was found for time in the SEG. The post hoc $t$ test showed that the SEG both Gmed and CEG Lt. Gmed significantly increased post-intervention versus pre-intervention (Table 2).

However, no significant difference pre- and post-intervention was observed in the Gmax muscle strength in SEG and CEG (Figure 4). The SEG Gmax and CEG Gmax had no significant differences pre- and post-intervention in both groups and no significant differences between groups (Figure 5).

A significant time-by-group interaction was found and gait velocity (Table 2) significantly increased post-intervention versus pre-intervention in the SEG. An independentsample $t$-test demonstrated that gait velocity significantly increased post-intervention versus pre-intervention in the SEG compared to the CEG (Figure 5).

A significant time-by-group interaction was found for the VAS (Table $2 ; 6.63 \pm 2.18$ vs. $2.63 \pm 1.14, p<0.001$ ), and KODI (Table 2; $31.19 \pm 15.60$ vs. $17.00 \pm 6.99, p<0.001$ ) significantly decreased post-intervention versus pre-intervention in the SEG. A significant main effect for time was observed for pain and low back disability in both groups. The post hoc $t$-test showed that VAS scores significantly decreased post-intervention versus pre-intervention in both
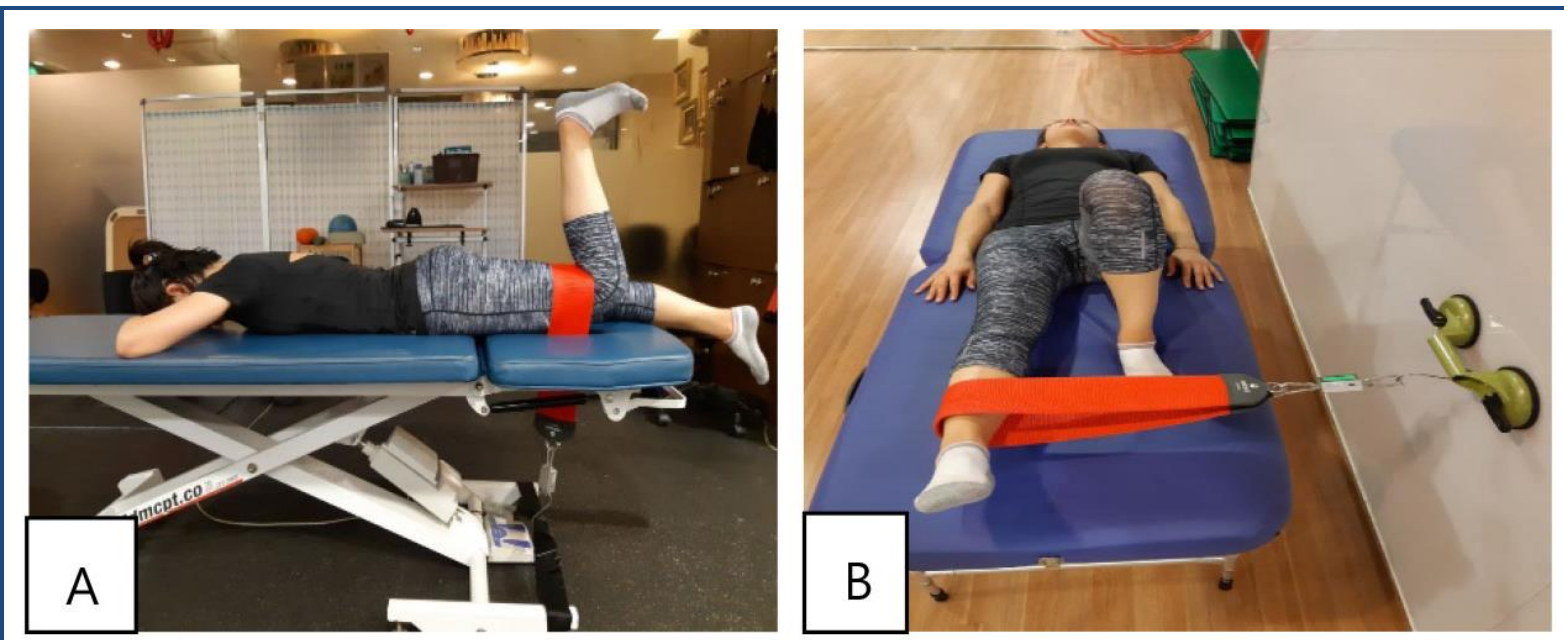

Figure 3. Gluteal muscle strength measurement. A: Gluteus maximus, B: Gluteus medius. 
Table 2. Change in gluteal muscle strength, gait velocity, pain and low back disability pre- and post-intervention

\begin{tabular}{|c|c|c|c|c|c|c|c|}
\hline \multirow[t]{2}{*}{ Variable } & \multirow[t]{2}{*}{ Group } & $\begin{array}{c}\text { Pre- } \\
\text { intervention }\end{array}$ & $\begin{array}{c}\text { Post- } \\
\text { intervention }\end{array}$ & $\begin{array}{l}\text { Within-group } \\
\text { change }\end{array}$ & $\begin{array}{l}\text { Between-group } \\
\text { change }\end{array}$ & \multirow{2}{*}{\multicolumn{2}{|c|}{$p$}} \\
\hline & & Mean \pm SD & Mean \pm SD & \multicolumn{2}{|c|}{ Mean difference $(95 \% \mathrm{CI})$} & & \\
\hline \multirow{2}{*}{ Rt. Gmax } & SEG $(n=16)$ & $5.85 \pm 3.12$ & $6.96 \pm 3.18$ & $1.10(-2.33,0.12)$ & \multirow{2}{*}{$0.41(-1.44,2.27)$} & 0.07 & \multirow{2}{*}{0.83} \\
\hline & CEG $(n=11)$ & $6.50 \pm 3.55$ & $8.01 \pm 3.20$ & $1.51(-3.05,0.02)$ & & 0.12 & \\
\hline \multirow{2}{*}{ Lt. Gmax } & SEG $(n=16)$ & $6.28 \pm 3.98$ & $7.07 \pm 3.43$ & $0.78(-2.02,0.44)$ & \multirow{2}{*}{$0.22(-1.55,2.00)$} & 0.19 & \multirow{2}{*}{0.78} \\
\hline & CEG $(n=11)$ & $6.96 \pm 3.92$ & $7.97 \pm 3.59$ & $1.00(-2.37,0.35)$ & & 0.38 & \\
\hline \multirow{2}{*}{ Rt. Gmed } & SEG $(n=16)$ & $4.57 \pm 1.48$ & $5.83 \pm 1.78$ & $1.25(-2.02,0.44)$ & \multirow{2}{*}{$-0.81(1.48,0.15)$} & $0.00^{*}$ & \multirow{2}{*}{0.37} \\
\hline & CEG $(n=11)$ & $4.28 \pm 2.24$ & $4.71 \pm 2.45$ & $0.43(-0.88,0.01)$ & & 0.55 & \\
\hline \multirow{2}{*}{ Lt. Gmed } & SEG $(n=16)$ & $4.46 \pm 1.61$ & $5.11 \pm 1.78$ & $0.65(-0.88,-0.41)$ & \multirow{2}{*}{$-0.24(0.62,0.02)$} & $0.00^{*}$ & \multirow{2}{*}{$0.00^{*}$} \\
\hline & CEG $(n=11)$ & $4.18 \pm 2.01$ & $4.60 \pm 2.18$ & $0.33(-0.64,-0.19)$ & & $0.00^{*}$ & \\
\hline \multirow{2}{*}{$\begin{array}{c}\text { Gait } \\
\text { velocity }\end{array}$} & SEG $(n=16)$ & $1.11 \pm 0.11$ & $1.41 \pm 0.18$ & $0.29(-0.36,-0.14)$ & \multirow{2}{*}{$0.25(-0.34,0.16)$} & $0.00^{*}$ & \multirow{2}{*}{$0.00^{*}$} \\
\hline & $\operatorname{CEG}(n=11)$ & $1.14 \pm 0.12$ & $1.18 \pm 0.11$ & $0.03(-0.34,-0.16)$ & & $0.01^{*}$ & \\
\hline \multirow{2}{*}{ VAS $(\mathrm{cm})$} & SEG $(n=16)$ & $6.63 \pm 2.18$ & $2.63 \pm 1.14$ & $4.00(2.86,5.13)$ & \multirow{2}{*}{$1.54(-1.21,3.21)$} & $0.00^{*}$ & \multirow{2}{*}{$0.00^{*}$} \\
\hline & CEG $(n=11)$ & $4.72 \pm 2.68$ & $2.27 \pm 1.19$ & $2.45(1.13,3.77)$ & & $0.00^{*}$ & \\
\hline \multirow{2}{*}{ KODI (\%) } & SEG $(n=16)$ & $31.19 \pm 15.60$ & $17.00 \pm 6.99$ & $14.18(8.47,19.90)$ & \multirow{2}{*}{$9.00(0.86,17.14)$} & $0.00^{*}$ & \multirow{2}{*}{0.03} \\
\hline & CEG $(n=11)$ & $18.45 \pm 12.63$ & $13.27 \pm 6.37$ & $5.18(-0.90,11.27)$ & & 0.55 & \\
\hline
\end{tabular}

Data are expressed as mean \pm standard deviation; ${ }^{*} p<0.05$.

Abbreviations: SEG, sling exercise group; CEG, common exercise group; Gmax, gluteus maximus; Gmed, gluteus medius; VAS, visual analog scale; KODI, Korean Oswestry Disability Pain Index; SD, standard deviation; CI, confidence interval; Rt, right; Lt, left.

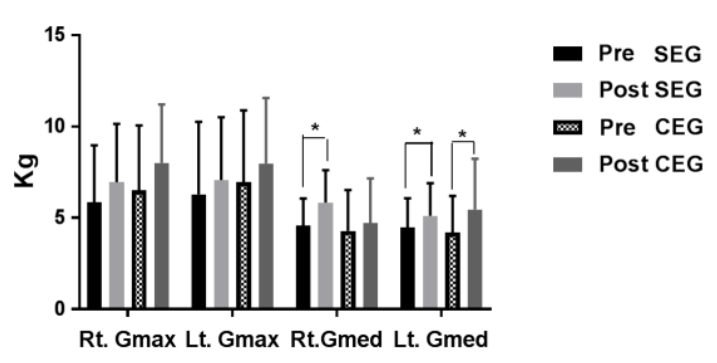

Figure 4. Change in gluteal muscle strength pre- and post-intervention. ${ }^{*} p<0.05$. SEG, sling exercise group; CEG, common exercise group; Gmax, gluteus maximus; Gmed, gluteus medius; Rt, right; Lt, left.

groups (Table 2). The post hoc $t$-test showed that total KODI scores significantly decreased post-intervention versus pre-intervention in both groups. (Table 2). An independentsample $t$-test demonstrated that KODI (Table 2; $F=2.090$, $p=0.032$, mean difference $=9.00$ ) significantly decreased in the SEG compared to the CEG.

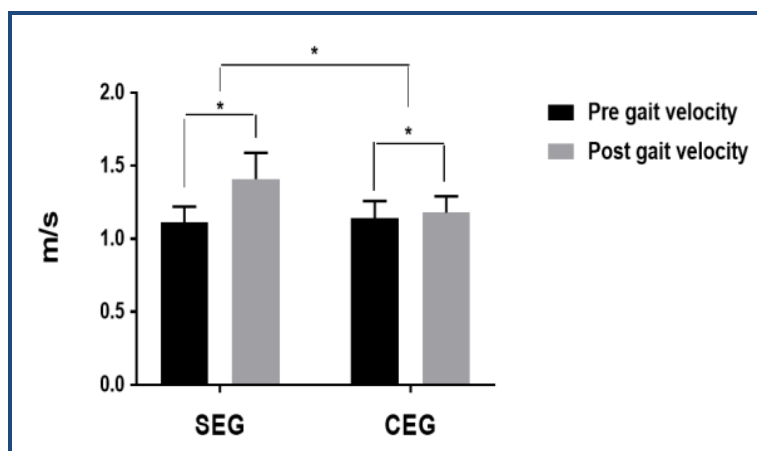

Figure 5. Change in gait velocity pre- and post-intervention. ${ }^{*} p<0.05$. SEG, sling exercise group; CEG, common exercise group. Gmax, gluteus maximus; Gmed, gluteus medius.

\section{DISCUSSION}

We investigated the effects of sling exercise for four weeks on gluteal muscle strength, gait velocity, pain, and low back disability function in those with a history of CLBP. Our results showed that both the SEG and the CEG 
experienced less pain and increased gait velocity. However, Gmed muscle strength and KODI improvements were only observed in the SEG. These results confirm that both interventions lead to pain relief and improved gait speed, but only SEG increased the Gmed muscle strength and decreased low back disability. These findings indicate that sling exercise should be recommended in the rehabilitation program for those with a history of CLBP to improve gluteal muscle strength and gait velocity.

The SEG showed improvements in the only Gmed muscle strength. There are several possible reasons for the increased Gmed muscle strength. First, sling hip bridge exercise was originated to improve trunk and back muscle strength other than for gluteal muscle strength. Previous research investigated the effect of sling exercise for strengthening of the trunk muscles for those with low back pain and other studies on sling bridge exercise could improve the Gmax muscle strength. ${ }^{18,19,21}$ It is necessary to study whether the sling bridge is helpful in improving Gmax muscle strength.

Second, the length-tension relationship produces muscle force. Altered muscle length affects the joint kinematics and muscle activation can produce a certain degree of muscle force. ${ }^{29}$ Sling hip bridge exercise is performed on both legs, with extension to supporting straps. Therefore, both legs' knee extension positioning is longer than hamstring muscle length knee flexion position so this positioning is likely to produce compensatory strategies in muscle contraction during the sling hip bridge. Thus, Gmax cannot gain proper muscle contraction. Youdas et al. reported significantly decreased hamstring muscle activation with knee flexion for one-leg bridge compared with a knee extension bridge exercise. ${ }^{7}$ Therefore, altered positioning and joint kinematics can produce a certain degree of muscle force and affect muscle contraction. ${ }^{29}$ Future research on which exercise method provides more improvement to the Gmax muscle strength and correlation between the SEG to CEG with a history of CLBP.

Based on previous studies, strengthening of the Gmed muscle is effective for pain relief and movement pattern in subjects with low back pain. ${ }^{10}$ As a result, strengthening of the Gmed through the sling exercise may help subjects with low back pain. Previous researchers have investigated that the Gmed provides more stabilizing muscle activation than Gmax during the slow gait velocity. ${ }^{6}$ In this study, gait velocity was increased in the SEG compared with CEG, and the slow period of gait velocity from 1 to $2 \mathrm{~m} / \mathrm{s}$. Also, when walking speed increases, Gmed has a unique role in controlling lower limb acceleration and stabilizing. Increased contributions of Gmed muscles are therefore required to provide stability and propulsion when walking speed increases. ${ }^{30}$ Thus, there are more effects from Gmed muscle strength than Gmax during the slow period gait parameter. In addition, previous studies have demonstrated that the gait velocity increased by the pelvis rotation movement pattern. ${ }^{11,15,16,31}$ However, low back pain patients not used to pelvis rotation that alters movement strategy are encouraged to slowly increase gait velocity and avoid pain caused by the pelvis rotation. ${ }^{11,16}$ This study could not confirm a significant difference in the VAS pre-intervention and postintervention in either group. Based on this result, we suggest pain relief of the CLBP by strengthening the lumbopelvic-hip complex muscles contributes to preventing uncontrolled rotation of the pelvis during the gait. Also, the gait velocity was increased in both groups. It was found that the pelvis movement was increased during the gait because of the pain relief and that the SEG showed faster gait velocity than the control group. However, in previous studies, the presence of gluteal muscle pain does not necessarily limit hip joint functional movement for middleaged women. ${ }^{32}$ Therefore, It is difficult to confirm a direct influence between pain relief and increased gait velocity.

Thus, based on our findings, we can expect that sling exercises are more effective for stabilizing the lumbopelvic-hip complex than general exercises and are effective in relieving pain, functional improvement of low back pain, increasing gluteal muscle strength, and increasing gait velocity. The present study had several limitations. First, we did not measure gluteal muscle activation. Future studies are required to investigate the differences between Gmax and Gmed muscle activity in the two interventions. Second, we measure only female subjects.

\section{CONCLUSIONS}

This study investigated the effects of sling exercise on gluteal muscle strength, gait velocity, pain, and low back disability in those with a history of CLBP. The SEG showed improved Gmed muscle strength, low back disability, and gait velocity compared to the CEG. These results suggest that the sling exercise is a more effective program for strengthening Gmed muscles and for low back disability and gait velocity, in particular in those with CLBP.

\section{Key Points}

Question Whether sling exercises can be used to increase gait velocity and gluteal muscle strength in those with chronic low back pain (CLBP). 
Findings The sling exercise showed improved gluteus medius muscle strength and gait velocity compared to common exercise with in CLBP. These results show that hip abductor strength was significantly different between before and after sling exercise.

Meaning Sling exercises may be effective for stability during the gait pattern and may be recommended to improve the gluteal strength and lumbo-pelvic stability for those with CLBP.

\section{Article information}

Conflict of Interest Disclosures: None.

Funding/Support: None.

Acknowledgment: None.

Ethic Approval: The study was approved by the Institutional Research Review Committee of Inje University (INJE 2018-04-036-005).

\section{REFERENCES}

1. Macadam P, Cronin J, Contreras B. An examination of the gluteus muscle activity associated with dynamic hip abduction and hip external rotation exercise: a systematic review. Int J Sports Phys Ther. 2015;10(5):573-591.

2. Amabile AH, Bolte JH, Richter SD. Atrophy of gluteus maximus among women with a history of chronic low back pain. PLoS One. 2017;12(7):e0177008.

3. Koes BW, van Tulder MW, Thomas S. Diagnosis and treatment of low back pain. BMJ. 2006;332(7555):14301434.

4. Panjabi MM. Clinical spinal instability and low back pain. J Electromyogr Kinesiol. 2003;13(4):371-379.

5. Added MAN, de Freitas DG, Kasawara KT, Martin RL, Fukuda TY. Strengthening the gluteus maximus in subjects with sacroiliac dysfunction. Int J Sports Phys Ther. 2018;13(1):114-120.

6. Lee SK, Lee SY, Jung JM. Muscle activity of the gluteus medius at different gait speeds. $J$ Phys Ther Sci. 2014; 26(12):1915-1917.

7. Youdas JW, Hartman JP, Murphy BA, Rundle AM, Ugorowski JM, Hollman JH. Electromyographic analysis of gluteus maximus and hamstring activity during the supine resisted hip extension exercise versus supine unilateral bridge to neutral. Physiotherapy Theory and Practice. 2017;33(2):124-130.

8. Lee SW, Kim SY. Effects of hip exercise for chronic low back pain patients with lumbar instability. Phys Ther Sci. 2015;27(2):345-348.

9. Lamoth CJ, Stins JF, Pont M, Kerckhoff F, Beek PJ.
Effects of attention on the control of locomotion in individuals with chronic low back pain. J Neuroeng Rehabil. 2008;25(5):13.

10. Cooper NA, Scavo KM, Strickland KJ, et al. Prevalence of gluteus medius weakness in people with chronic low back pain compaired to healthy controls. Eur Spine $J$. 2016;25:1258-1265.

11. Henchoz Y, Soldini N, Peyrot N, Malatesta D. Energetic and mechanics of walking in patients with chronic low back pain and healthy matched controls. Eur J Appl Physiol. 2015;115:2433-2443.

12. Sidorkewicz N, Cambridge ED, McGill SM. Examining the effects of altering hip orientation on gluteus medius and tensor fascae latae interplay during common nonweight-bearing hip rehabilitation exercises. Clin Biomech (Bristol, Avon). 2014;29(9):971-976.

13. Barzilay Y, Segal G, Lotan R, et al. Patients with chronic non-specific low back pain who reported reduction in pain and improvement in function also demonstrated an improvement in gait pattern. Eur Spine J. 2016;25(9):2761-2766.

14. Khodadadeh S, Einstein SM. Gait analysis of patients with low back pain before and after surgery. Spine. 1993;18:1451-1455.

15. Bruijn SM, Meijer OG, van Dieën JH, Kingma I, Lamoth CJ. Coordination of leg swing, thorax rotations, and pelvis rotations during gait: the organisation of total body angular momentum. Gait \& Posture. 2008;27(3): 455-462.

16. Lamoth CJ, Meijer OG, Wuisman PI, van Dieën JH, Levin MF, Beek PJ. Pelvis-thorax coordination in the transverse plane during walking in persons with nonspecific low back pain. Spine (Phila Pa 1976). 2002; 27(4):E92-99.

17. Lamoth CJ, Daffertshofer A, Meijer OG, Lorimer Moseley G, Wuisman PI, Beek PJ. Effects of experimentally induced pain and fear of pain on trunk coordination and back muscle activity during walking. Clin Biomech. 2004;19(6):551-563.

18. Roh HS, Cho WJ, Ryu WJ, Park SJ, An CS. The change of pain and lumbosacral sagittal alignment after sling exercise therapy for patients with chronic low back pain. J Phys Ther Sci. 2016;28(10):2789-2792.

19. You YL, Su TK, Liaw LJ, Wu WL, Chu IH, Guo LY. The effect of six weeks of sling exercise training on trunk muscular strength and endurance for clients with low back pain. J Phys Ther Sci. 2015;27(8):2591-2596.

20. Kang H, Jung J, Yu J. Comparison of trunk muscle activity during bridging exercise using a sling in patient with low back pain. J Sports Sci Med. 2012;11(3):510- 
515.

21. Yue YS, Wang XD, Xie B, et al. Sling exercise for chronic low back pain: a systematic review and metaanalysis. PLoS One. 2014;11;9(6):e993079.

22. Kim JH, Kim YE, Bae SH, Kim KY. The effect of neurac sling exercise on postural balance adjustment and muscular response patterns in chronic low back pain patients. J Phys Ther Sci. 2013;25(8):1015-1019.

23. Price DD, McGrath PA, Rafii A, Buckingham B. The validation of visual analogue scales as ratio scale measures for chronic and experimental pain. Pain. 1983; 17(1):45-56.

24. Carlsson AM. Assessment of chronic pain. I. Aspects of the reliability and validity of the visual analogue scale. Pain. 1983;16(1):87-101.

25. Kim GM, Yi CH, Cynn HS. Factor influencing disability due to low back pain using the oswestry disability questionnaire and the quebec back pain disability scale. Physiother. Res. Int. 2015;20:16-21.

26. Kim DY, Lee SH, Lee HY, et al. Validation of the Korean Version of the Oswestry Disability Index. Spine (Phila Pa 1976). 2005;30(5):E123-127.

27. van der Linden ML, Aitchison AM, Hazlewood ME, Hillman SJ, Robb JE. Test-retest repeatability of gluteus maximus strength testing using a fixed dynamometer in children with cerebral palsy. Arch Phys Med Rehabil. 2004;85(12):2058-2063.

28. Thorborg K, Bandholm T, Hölmich P. Hip and kneestrength assessments using a hand-held dynamometer with external belt-fixation are inter-tester reliable. Knee Surg Sports Traumatol Arthrosc. 2013;21:550-555.

29. Neumann DA. Kinesiology of the musculoskeletal system: foundations for physical rehabilitation. St. Louis, Mosby. 2002.

30. Jansen K, De Groote F, Duysens J, Jonkers I. How gravity and muscle action control mediolateral center of mass excursion during slow walking: a simulation study. Gait Posture. 2014;39(1):91-97.

31. Crosbie J, de Faria Negrão Filho R, Nascimento DP, Ferreira P. Coordination of spinal motion in the transverse and frontal planes during walking in people with and without recurrent low back pain. Spine (Phila $\mathrm{Pa}$ 1976). 2013;38(5):E286-292.

32. Hatton AL, Hug F, Chen SH, Reid C, Sorensen NA, Tucker K. The effects of acute experimental hip muscle pain on dynamic single-limb balance performance in healthy middle-aged adults. Gait \& Posture. 2016;05: 201-206. 